University of Nebraska - Lincoln

DigitalCommons@University of Nebraska - Lincoln

$4-22-2009$

\title{
A NEW GENUS OF MOSS-INHABITING FLEA BEETLES (COLEOPTERA: CHRYSOMELIDAE) FROM NICARAGUA
}

Alexander S. Konstantinov

Maria Lourdes Chamorro-Lacayo

Vilma P. Savini

Follow this and additional works at: https://digitalcommons.unl.edu/usdaarsfacpub

This Article is brought to you for free and open access by the U.S. Department of Agriculture: Agricultural Research Service, Lincoln, Nebraska at DigitalCommons@University of Nebraska - Lincoln. It has been accepted for inclusion in Publications from USDA-ARS / UNL Faculty by an authorized administrator of DigitalCommons@University of Nebraska - Lincoln. 


\title{
A New Genus of Moss-Inhabiting Flea Beetles (Coleoptera: Chrysomelidae) from Nicaragua
}

Alexander S. Konstantinov

Systematic Entomology Laboratory, PSI, Agricultural Research Service U.S. Department of Agriculture, c/o Smithsonian Institution, P.O. Box 37012

National Museum of Natural History

MRC 168, Washington, DC 20013-7012, USA

alex.konstantinov@ars.usda.gov

Maria Lourdes Chamorro-Lacayo

Department of Entomology

University of Minnesota

Saint-Paul, MN 55108, USA

cham0138@umn.edu

AND

Vilma P. SAVini

Museo del Instituto de Zoología Agricola

Facultad de Agronomía

Universidad Central de Venezuela

Apdo 4579, Maracay 2101-A

Estado Aragua, VENEZUELA

vsgioia@gmail.com

\begin{abstract}
Nicaltica new genus and new species ( $N$. selvanegra Konstantinov, Chamorro-Lacayo and Savini) from moss habitat in Nicaragua are described and illustrated. Nicaltica is compared to Kiskeya Konstantinov and Chamorro-Lacayo, Monotalla Bechyné, and Normaltica Konstantinov.
\end{abstract}

Moss and leaf litter constitute a specific environment for leaf beetles (Chrysomelidae) which normally are found on the foliage of the flowering plants on which they feed. Among the approximately 50,000 species of leaf beetles worldwide, only about 40 species are known to inhabit mosses. They all are flea beetles (Alticini), a group of about 11,000 species worldwide. So far the only known New World flea beetles living in mosses, two species of Kiskeya Konstantinov and Chamorro-Lacayo, were found in the Dominican Republic. Recent collecting in Nicaragua revealed another, previously unknown, genus described below.

Beetles were retrieved from sifted moss samples by Berlese extraction. Dissecting techniques and terminology for most internal and external structures follow Konstantinov (1998). Terminology for thoracic structures follows ChamorroLacayo and Konstantinov (2004). Specimens are deposited in the collection of the National Museum of Natural History, Smithsonian Institution, Washington, D.C. (USNM) and Museo del Instituto de Zoología Agricola, Facultad de Agronomía, Universidad Central de Venezuela, Maracay (MIZA). 


\section{Nicaltica Konstantinov, Chamorro-Lacayo and Savini, new genus}

(Figs. 1-28)

Description. Body length $1.38-1.55 \mathrm{~mm}$, width $1.05-1.15 \mathrm{~mm}$, rounded, convex in lateral view (1.78 times as long as thick). Color black without metallic luster, legs and antennae more pale.

Head (Figs. 3, 4, 11) nearly hypognathous, flat in lateral view. Frons and vertex forming slightly convex line (Fig. 11) in lateral view. Supraorbital pore well developed with no other pores nearby. Antennal calli well developed, very short, oblique, not connected to each other. Supracallinal sulcus deep, straight. Midfrontal sulcus absent. Suprafrontal and suprantennal sulci well developed, deep. Supraorbital sulcus slightly impressed ventrally, absent dorsally. Subgenal suture shallow dorsally, absent ventrally. Orbit 0.45 times as wide as transverse diameter of eye. Interantennal space as wide as transverse diameter of eye and 2.1 times as wide as transverse diameter of antennal socket. Frontal ridge wide. Anterofrontal ridge not separated from frontal ridge. Both ridges form swollen, loosely defined triangle covered with shallow, longitudinal wrinkles. Eyes slightly protruding laterally. Vertex sometimes with oval impression in middle. Labrum with six setiferous pores, apically deeply incised. Labium with three palpomeres per palpus, two distal palpomeres longer than wide. Maxillary palpus with four palpomeres, distal palpomere conical, slightly longer than preapical. Antenna with 11 antennomeres. First antennomere slightly wider and much longer that second. Third and fourth antennomeres much thinner than second. Distal antennomeres wider than third and fourth.

Pronotum (Fig. 6) 1.62 times wider than long (measured in middle), without impressions, covered with sharp slightly longitudinal punctures. Sides weakly rounded and relatively narrowly explanate, converging gradually from base to apex. Marginal anterolateral callosity 3.7 times shorter than lateral margin. Posterolateral callosity not protruding. Basal margin extends posteriorly, with distinct border. Procoxal cavity closed. Intercoxal prosternal process relatively wide, longitudinally channeled, parallel-sided, flat at apex (Fig. 7).

Mesoscutellum flat, broadly triangular (Fig. 1). Mesocoxae separated by both meso- and metasterna. Mesosternum covered by metasternum, vertical (Figs. 7, 8).

Metanotum with well developed medial groove (Fig. 10). Metasternum (Fig. 8) protruding anteriorly between mesocoxae, forming obtuse denticle at apex.

Elytron (Fig. 1) widest near mid-length. Humeral callus poorly developed. Elytral punctures arranged in nine rows. Space between last row and lateral margin convex. Interspaces with tiny punctures, shiny. Elytral apex narrowly rounded, surrounded by distinct border. Epipleura broad, oblique, gradually narrowing posteriorly, nearly attaining sutural margin of elytron. Lateral margin of elytron continued ventrally beyond epipleura near pronotum, delimiting epipleura dorsolaterally. Elytron with sensilla distributed evenly throughout surface, others concentrated in two sensilla patches (Figs. 13-17). Wing with a set of veins common in flea beetles (Konstantinov 2002), but CuA 3+4, RP-mp2, and RP poorly sclerotized and barely visible (Fig. 28).

Pro- and mesofemur slightly flattened dorsoventrally. Metafemur robust, flat dorsoventrally, fairly symmetrical (Fig. 12), 1.95 times as long as wide. Pro- and mesotibiae cylindrical, slightly wider in distal $1 / 3$, without spurs apically. Metatibia (Fig. 18) slightly curved in dorsal view, straight in lateral view, generally cylindrical, abruptly widening distally (in dorsal view), flat only at apex, 


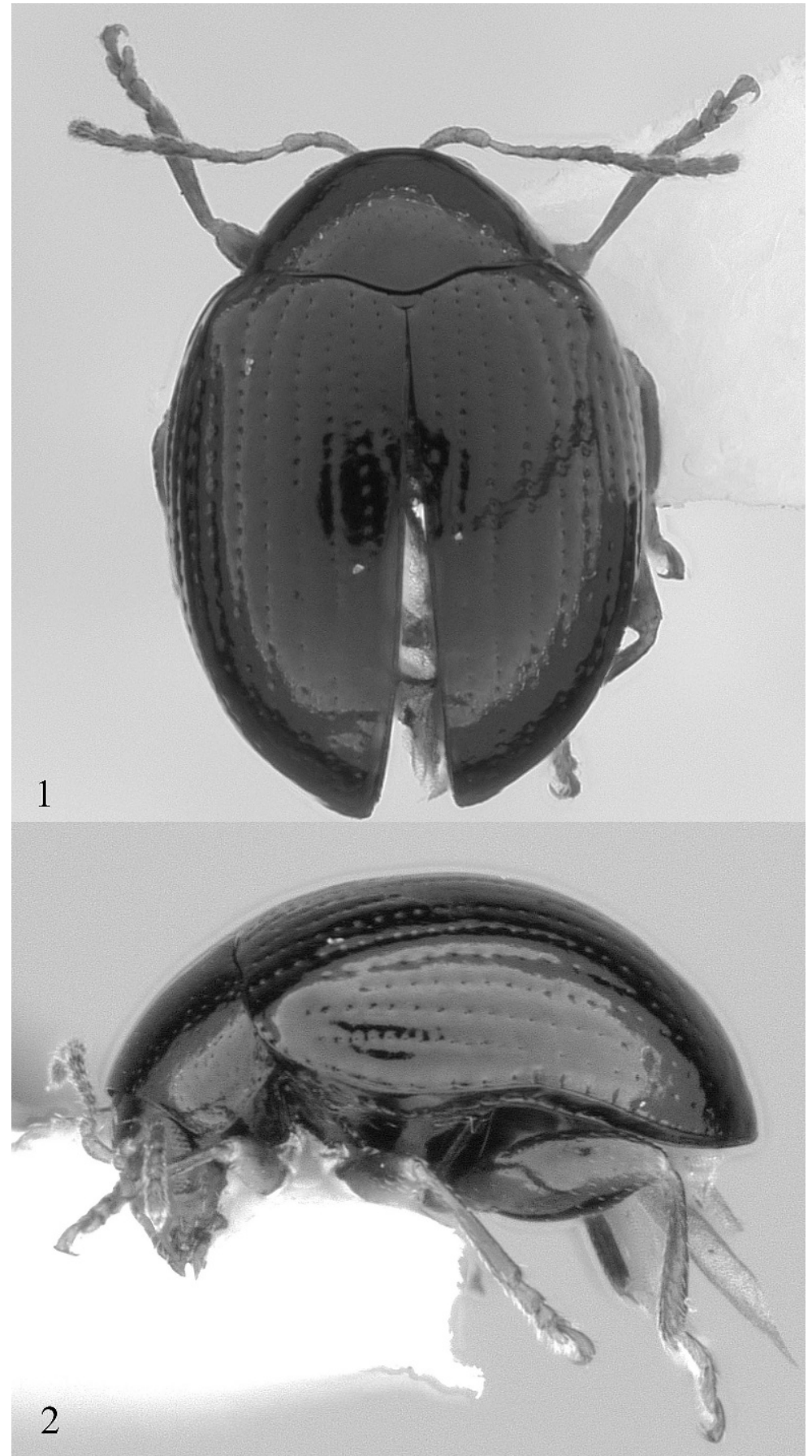

Figs. 1-2. Nicaltica selvanegra male, habitus. 1) dorsal view; 2) lateral view. 


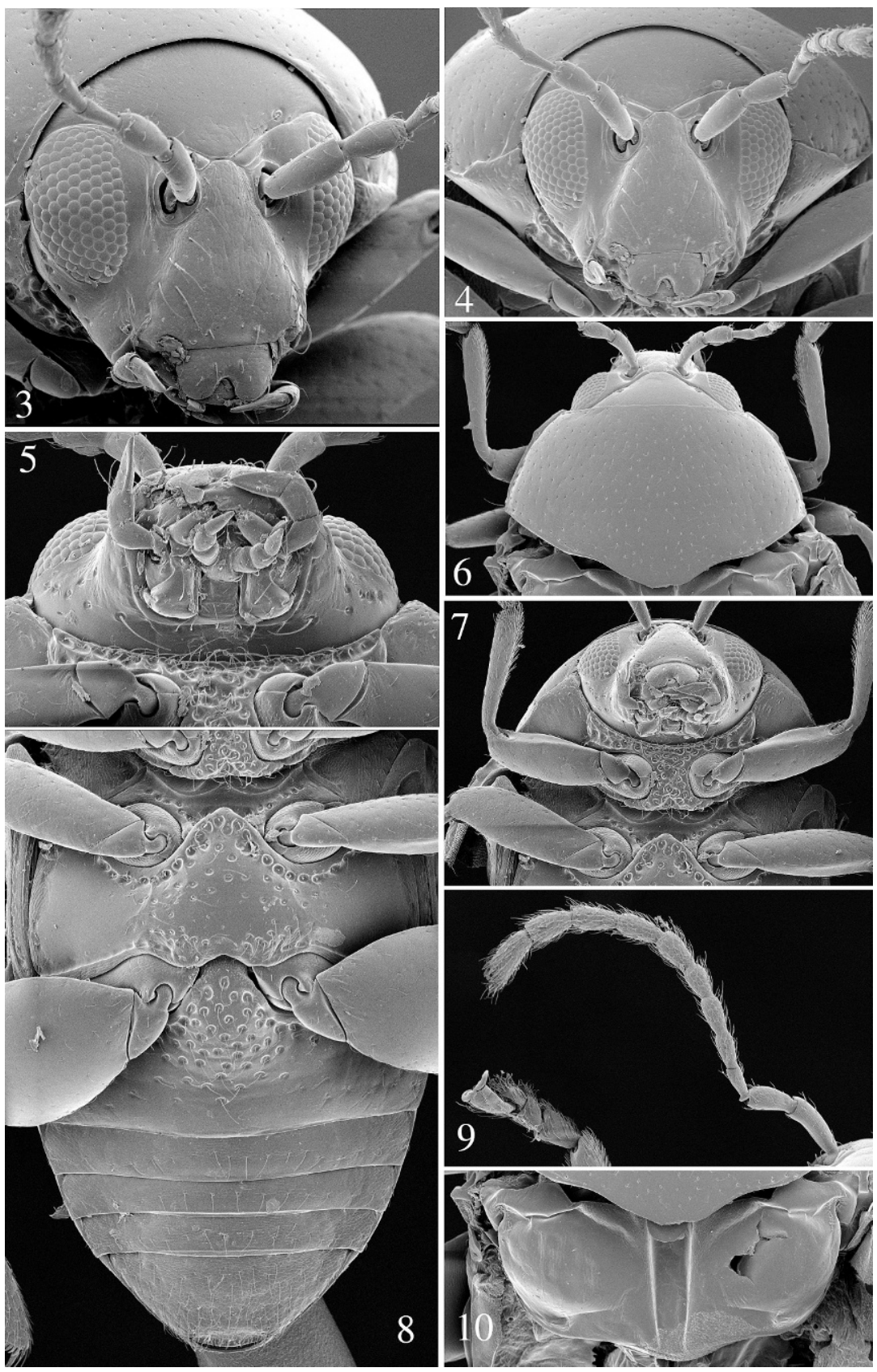

Figs. 3-10. Details of morphological structures of $N$. selvanegra. 3, 4) head, frontal view; 5) head, ventral view; 6) pronotum; 7) prothorax, ventral view; 8) metasternum and abdomen; 9) antenna; 10) metanotum. 

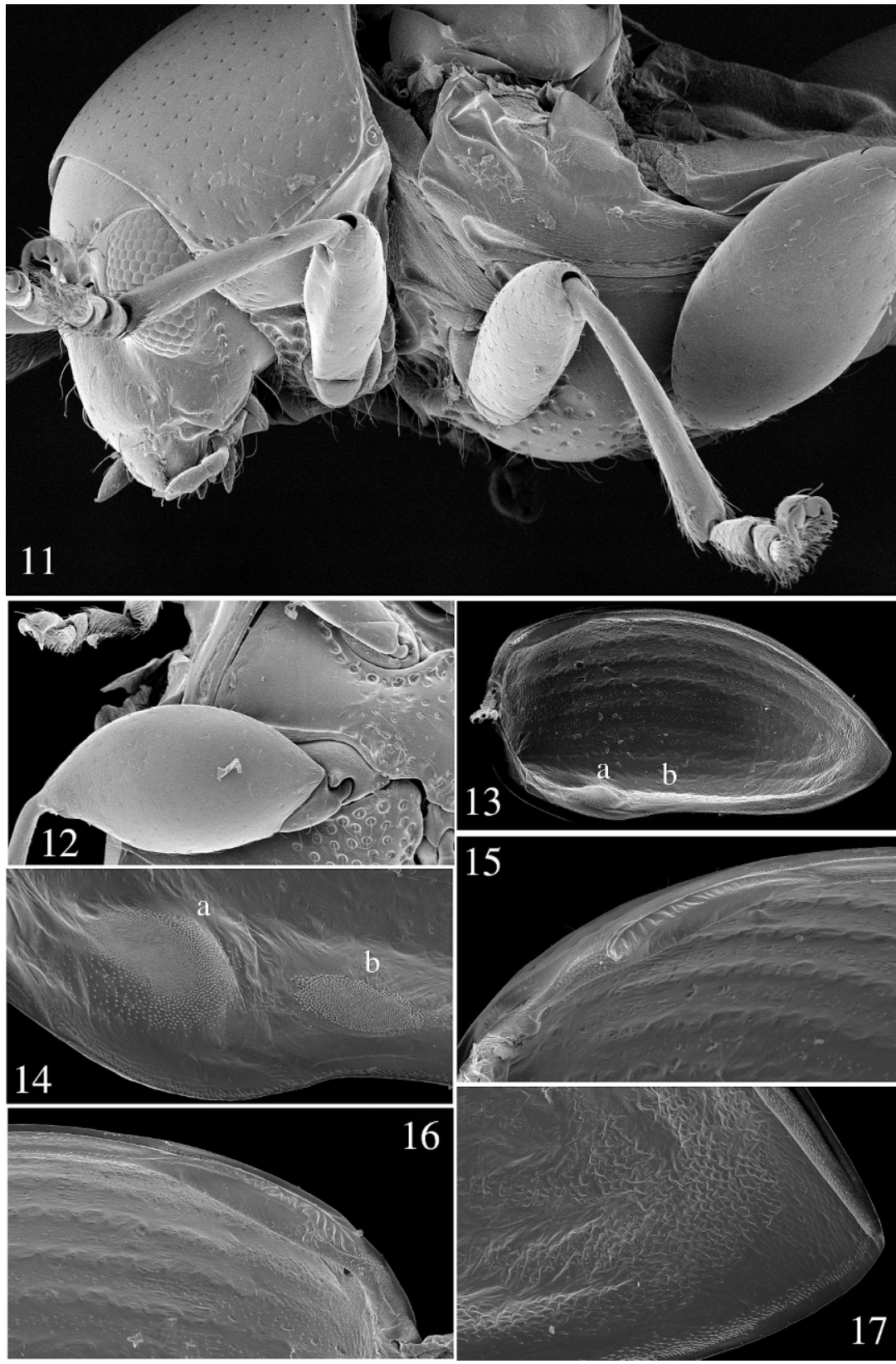

Figs. 11-17. Details of morphological structures of $N$. selvanegra. 11) head and thorax in lateral view; 12) metafemur; 13-17) internal side of elytron, a, b-sensilla patches. 


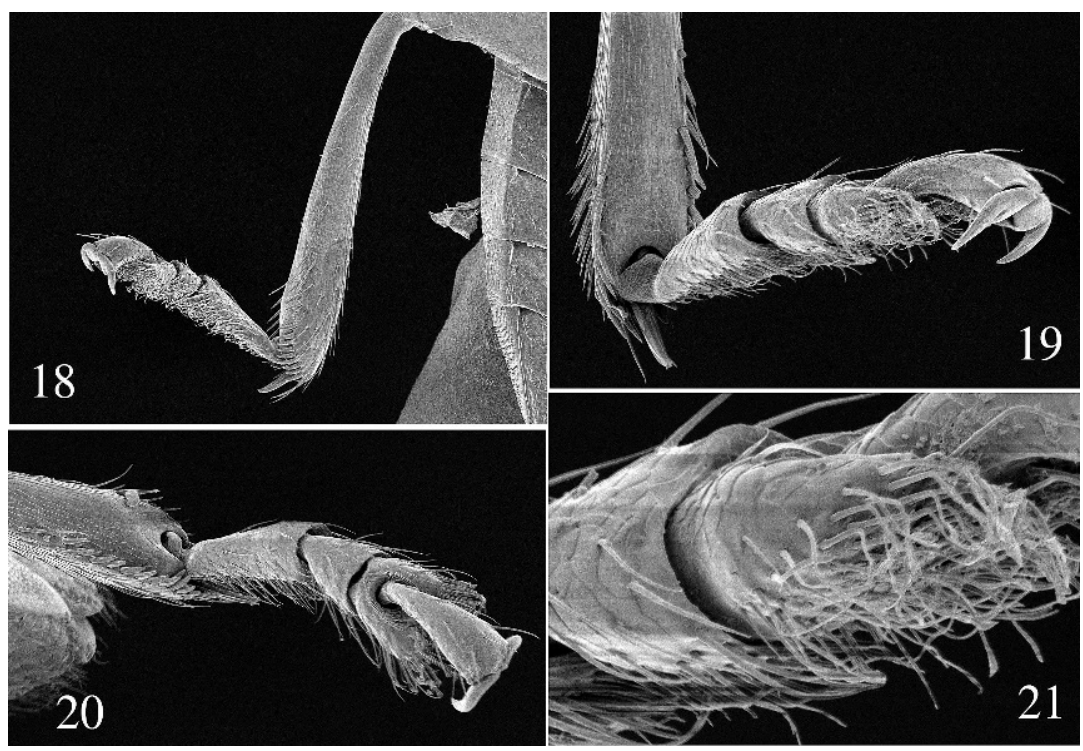

Figs. 18-21. Legs of $N$. selvanegra. 18) metatibia and tarsus; 19) metatibial apex and metatarsus in lateral view; 20) metatarsus in dorsal view; 21) setae on bottom of metatarsomere 3 .

without serration on the outer and inner edges and without preapical excavations on either inner or outer edges; apical spur as long as tarsal claw. Claw appendiculate (Fig. 19). Third tarsomere deeply incised (Fig. 20). First metatarsomere as long as two following tarsomeres together.

Abdomen with five distinctly visible sternites (Figs. 8, 26). Apical sternite as long as three preceding sternites combined, without appendages basally. Apical tergite of female broadly triangular, unevenly covered with long setae, weakly sclerotized in middle and at anterolateral corners, with sclerotized groove in middle (Fig. 24).

Spermatheca (Fig. 22) with receptacle gradually transitioning into pump without distinct border. Receptacle much longer and wider than pump. Duct straight, with base of gland situated nearly at mid length. Tignum (Fig. 23) narrowing anteriorly, slightly narrower than posteriorly. Vaginal palpi (Fig. 25) slender, connected on distal $1 / 3$, distal sclerotizations narrow and curved.

Median lobe of aedeagus (Fig. 27) simple, convex in lateral view, without any sculpture ventrally.

Type species. Nicaltica selvanegra Konstantinov, Chamorro-Lacayo and Savini.

Etymology. This genus name is derived from the country in which these beetles occur, Nicaragua, and the name of the type genus of the tribe. The name is feminine.

Figs. 22-27. Details of morphological structures of $N$. selvanegra. 22) spermatheca; 23) tignum; 24) apical abdominal tergite; 25) vaginal palpi; 26) abdominal ventrites; 27) median lobe of the aedeagus. 

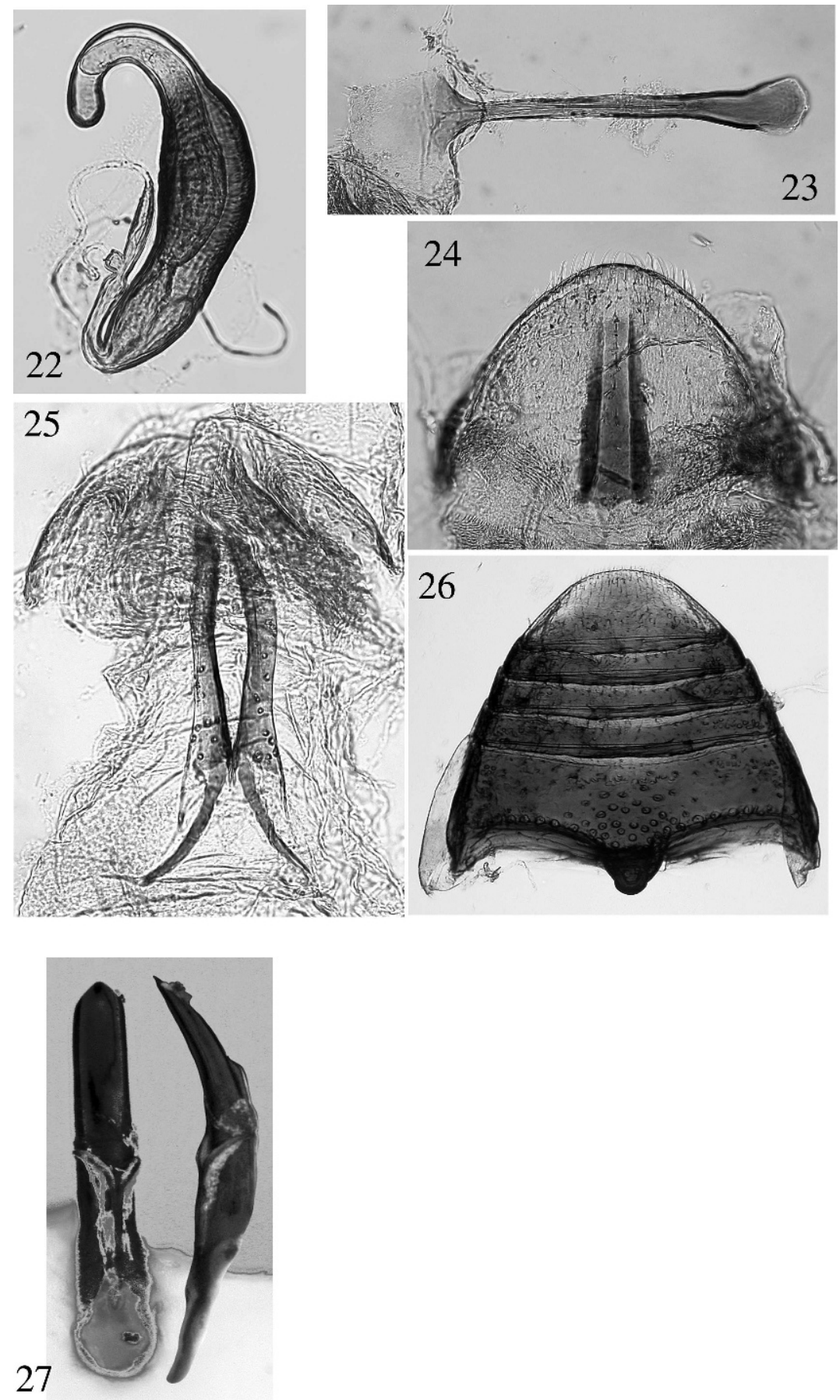


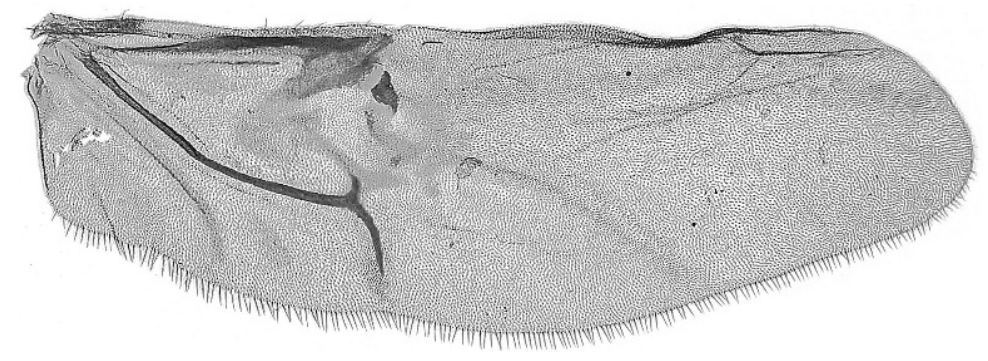

Fig. 28. Wing of $N$. selvanegra.

Host plant. Unidentified mosses (Fig. 30), although feeding was not observed.

Diagnosis and comparison. Based on the general shape of the body, shape of the base of the pronotum with a lobe extending posteriorly, metatibia and tarsal claw, Nicaltica is similar to Normaltica (Konstantinov 2002). It can be easily distinguished by the unique shape of the antennal calli, which are short and oblique, delineated from the vertex by the deep supracallinal sulcus (in Normaltica the antennal calli are long and poorly separated from the vertex); frontal and anterofrontal ridges forming a swollen triangle (in Normaltica the frontal and anterofrontal ridges form a rectangular structure); mostly filiform antennae (in Normaltica the antennae are clavate); deeply incised labrum (it is solid in Normaltica); mesosternum covered by metasternum (it is not covered in Normaltica); slender vaginal palpi (they are robust in Normaltica), and generally less sclerotized wing, particularly $\mathrm{CuA} 3+4$ vein (Fig. 28).

Nicaltica is superficially similar to Kiskeya (Konstantinov and ChamorroLacayo 2006) and Monotalla Bechyné (Savini and Furth 2001). Among features that most readily separate Nicaltica from Kiskeya and Monotalla are 11segmented, filiform antennae (they are 9- and 10-segmented accordingly and also clavate in Kiskeya); the head with a nearly full set of sulci (most sulci, supracallinal in particular, are absent in Kiskeya and Monotalla); the first abdominal sternite lacking a longitudinal ridge (the ridge is present in Kiskeya); and the metatibia nearly cylindrical (it is flattened dorsoventrally with longitudinal groove on the dorsal side in Kiskeya and Monotalla).

The meso- and metasternites of Nicaltica are as short as in most flightless flea beetles, so we very much doubt that the flight muscles are significantly developed. Although these beetles have wings (Fig. 28), they probably cannot fly, as in the case of some Neotropical cicindelines (Zerm and Adis 2002).

\section{Nicaltica selvanegra Konstantinov, Chamorro-Lacayo and Savini, new species}

(Figs. 1-28)

Description. Body length $1.38-1.55 \mathrm{~mm}$, width $1.05-1.15 \mathrm{~mm}$. Color black without metallic luster. Legs and last 5 antennomeres dark brown, remainder of antenna dark yellow. Vertex smooth, without punctures, covered with shallow, oblique wrinkles. Proportions of antennomere lengths in female: 15:9:9:8:8:9:9:10:9:10:15; in male: 15:11:8:7:8:7:9:10:9:10:15. Pronotum evenly covered with sharp, slightly longitudinal punctures. Distance between punctures many times more than diameter of puncture. Elytron with nine complete rows of 
punctures. Additional scutellar row incomplete. Distances between punctures in rows and between rows about three times diameter of puncture. Interspaces slightly shagreened, with only few, sparse, barely visible punctures. Middle of first abdominal ventrite covered with large punctures, remainder bare. Proportions of tarsomere lengths of female (starting with first): protarsomeres 10:6:7:15; mesotarsomeres 10:6:7:15; metatarsomeres 15:8:8:16. In male, proportions as follows: protarsomeres 11:7:8:13; mesotarsomeres 11:7:8:15; metatarsomeres 17:6:8:17.

Spermatheca (Fig. 22) with receptacle slightly constricted above one third. Spermathecal pump much shorter than receptacle, strongly curved. Spermathecal duct without loop away from receptacle. Tignum (Fig. 23) expanding into membranous sclerite anteriorly with two patches of setae on sides. Vaginal palpi (Fig. 25) with posterior sclerotizations narrow and curved outwards.

Median lobe of the aedeagus (Fig. 27) in lateral view with apex straight and in ventral view abruptly narrowing without well defined denticle.

Etymology. The specific epithet is a noun in apposition based on the type locality.

Ecology. Unidentified moss samples that contained $N$. selvanegra were collected in the forest from a variety of substrates (rocks, tree stumps, trunks and branches) (Figs. 29, 30).

Selva Negra is located with easy access to the virgin cloudforest of one of the highest peaks of the serranía Dariense, El Picacho $(1,580 \mathrm{~m})$. The serranía Dariense is one of three mountain ranges traversing the central Nicaraguan landscape. The mountain ranges gradually decrease in size from west to east into the large expanses of lowland rainforest along the Atlantic region of Nicaragua. The westernmost serranía Isabelia has the highest peaks, followed by the serranía Dariense, with the easternmost serranía Chontaleña reaching no more than 1,220 $\mathrm{m}$ (Cumaica) (Incer Barquero 2000). All three mountain ranges are separated by large river valleys. Several high and isolated peaks with similar forest and moss cover, on both the serranía Dariense and Isabelia, are located near Selva Negra / El Picacho, representing prime habitat for additional moss-inhabiting species of flea beetles. Some [cerro Saslaya $(1,651 \mathrm{~m})$ and cerro El Toro $(1,652 \mathrm{~m})$ ] are located at the edge of the one of the largest expanses of largely unexplored virgin forests in Mesoamerica, reserva de biosfera Bosawas $\left(8,000 \mathrm{~km}^{2}\right.$ ) (Incer Barquero 2000). Yet, within the serranía Dariense exist several high peaks much closer to El Picacho, which may also uncover additional Nicaltica individuals.

The Nicaltica specimens were collected from one collecting event during the early wet season in Selva Negra. This has been the first sampling of mosses in Central America. However, further moss sampling in the Neotropical region will undoubtedly reveal new material from mosses.

The massive peaks of the serranías act as barriers to the westerly winds of the Atlantic where the humidity falls in the form of rain or condenses on the highest peaks. The wet season in the central highlands region lasts between 7-8 months of the year with an annual precipitation of more than $2,000 \mathrm{~mm}$. The temperature on peaks above $1,500 \mathrm{~m}$ is above $20^{\circ} \mathrm{C}$ (Incer Barquero 2000).

Several peaks discussed above are located within national protected areas, such as Kilambe, Saslaya, and Peñas Blancas. The ever growing agricultural front threatens the forests, consequently the associated flora and fauna, on the majority of these peaks. Moss is directly affected as a result of deforestation either through direct downing of host trees or as a result of drying from loss of canopy cover and humidity retention. 


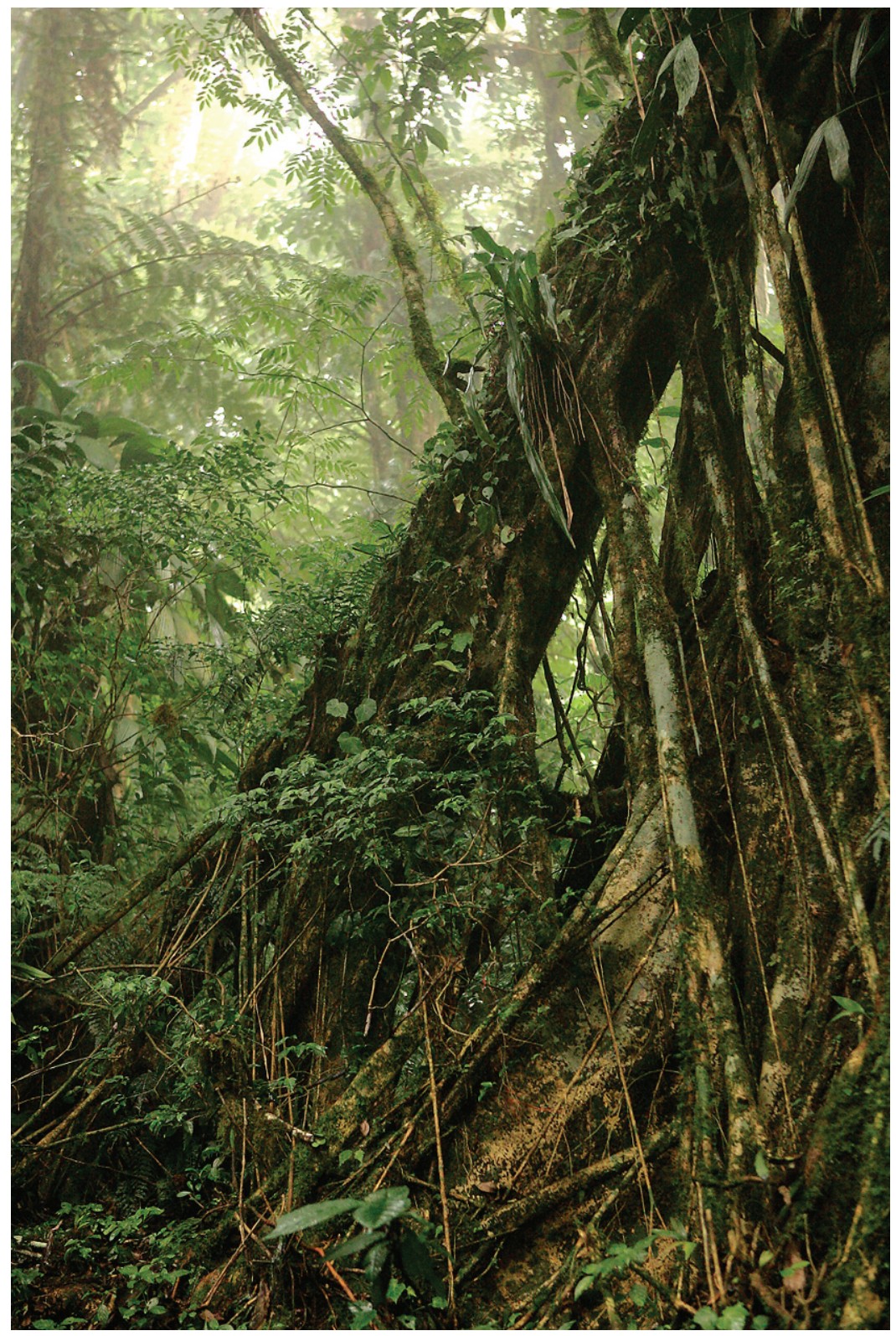

Fig. 29. Forest at Selva Negra reserve, habitat of N. selvanegra. Photo by R. Stanley. 


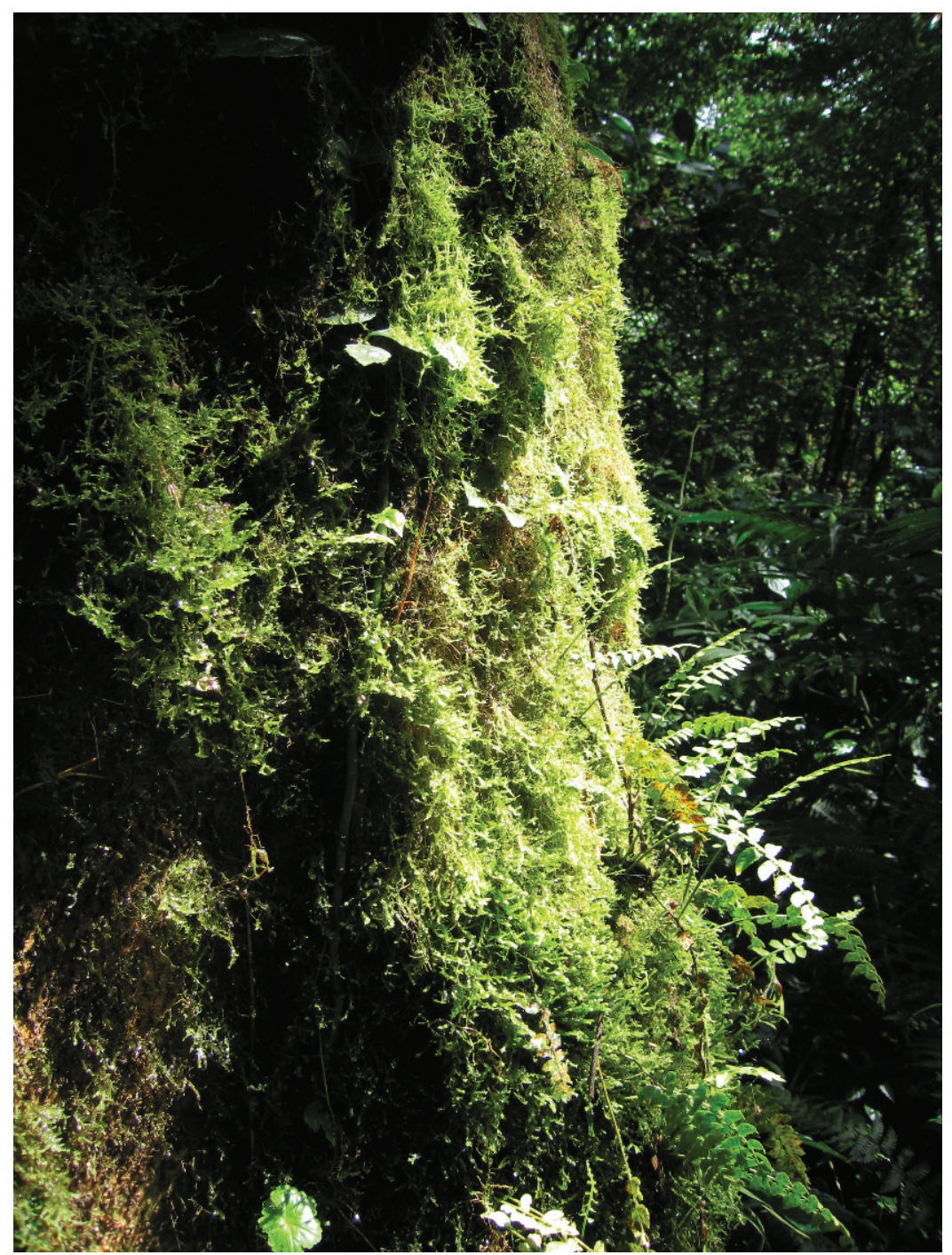

Fig. 30. Moss on a side of a tree, microhabitat of $N$. selvanegra. Photo by L. ChamorroLacayo.

Type material. Holotype male. Labels: 1) Nicaragua: Matagalpa Prov., $4.1 \mathrm{mi}$ N Matagalpa, Selva Negra $13^{\circ} 00^{\prime} 356^{\prime \prime} \mathrm{N}, 85^{\circ} 54^{\prime} 01^{\prime \prime} \mathrm{W}, 1,450 \mathrm{~m}$ 18-19.VI.2007, moss sifting, leg. A.Konstantinov \& L.Chamorro; 2) Holotype Nicaltica selvanegra des. A. Konstantinov, L. Chamorro \& V. Savini, 2008 (USNM). Paratypes: 3 females, 3 males, same labels as holotype (USNM), 2 males and 1 female (MIZA). 


\section{Acknowledgments}

We are grateful to S. Lingafelter, R. Stanley, and N. Woodley for companionship and comradery during the collecting trip to Nicaragua and to Jean-Michel Maes for his help in obtaining necessary permits.

We thank S. McKamey and A. L. Norrbom (Systematic Entomology Laboratory, ARS, USDA, Washington, DC), A. K. Tishechkin (Department of Entomology, Louisiana State University, Baton Rouge, LA) for reviewing earlier versions of this manuscript and providing useful suggestions, and $\mathrm{S}$. W. Lingafelter (Systematic Entomology Laboratory, ARS, USDA, Washington, DC) for valuable editorial suggestions.

\section{Literature Cited}

Chamorro-Lacayo, M. L., and A. S. Konstantinov. 2004. Morphology of the prothorax and procoxa in the New World Cryptocephalini (Coleoptera: Chrysomelidae: Cryptocephalinae). Zootaxa 676:1-46.

Incer Barquero, J. 2000. Geografia dinámica de Nicaragua (2nd ed.). Managua: Hispamer, $281 \mathrm{pp}$.

Konstantinov, A. S. 1998. Revision of the Palearctic species of Aphthona Chevrolat and cladistic classification of the Aphthonini (Coleoptera: Chrysomelidae: Alticinae). Memoirs on Entomology, International, Associated Publishers, Gainesville v.11:1-429.

Konstantinov, A. S. 2002. A new genus of flea beetles from the Greater Antilles (Coleoptera: Chrysomelidae). Zootaxa 124:1-24.

Konstantinov, A. S., and M. L. Chamorro-Lacayo. 2006. A new genus of moss-inhabiting flea beetles (Coleoptera: Chrysomelidae) from the Dominican Republic. The Coleopterists Bulletin 60(4):275-290.

Savini, V., and D. G. Furth. 2001. The status of Heikertingerella, Monotalla, Pseudodibolia, and Sphaeroderma (Coleoptera: Chrysomelidae: Alticinae) in the New World. Proceedings of the Entomological Society of Washington 103(4):903-912.

Zerm, M., and J. Adis. 2002. Flight ability in nocturnal tiger beetles (Coleoptera: Carabidae: Cicindelinae) from Central Amazonian floodplains (Brazil). The Coleopterists Bulletin 56(4):491-500.

(Received 22 June 2008; accepted 13 September 2008. Publication date 22 April 2009.) 